\title{
Characteristics of Immigrants Obtaining Abortions and Comparison with U.S.-Born Individuals
}

\author{
Sheila Desai, DrPH, Ellie Leong, BA, and Rachel K. Jones, PhD
}

\begin{abstract}
Background: Little information exists about individuals born outside of the United States who seek abortion services from U.S.-based providers. Baseline data are necessary to identify future changes in the profile of this population.

Materials and Methods: Using the Guttmacher Institute's Abortion Patient Survey, we pooled two national samples of individuals obtaining abortions from 2008-2009 to 2013-2014 to provide data on 17,873 respondents, $16 \%$ of whom were immigrants. We estimated the distribution of immigrant and U.S.-born respondents across demographic and circumstantial characteristics such as age, poverty level, and gestational age at abortion. We compared the distribution of characteristics by nativity status using chi-square tests.

Results: The majority of immigrants obtaining abortions were in their 20s (51\%), had poverty-level (50\%) or near poverty-level incomes (23\%), and had graduated from high school (78\%). Almost half (45\%) were uninsured and a similar proportion had been in the United States for less than 10 years (44\%); nearly one-quarter completed their survey in Spanish. Compared with U.S.-born respondents, a larger proportion of immigrants were older, uninsured, and had not completed high school. A smaller proportion of immigrants compared with nonimmigrants had their abortions after 12 weeks (8\% vs. 11\%) or traveled over 50 miles to obtain their abortion (9\% vs. 16\%).

Conclusions: Particularly with the continued rise in both restrictive abortion and immigration policies in the United States, it is critical to monitor how immigrants' use of and access to abortion services are impacted in the changing environment. Ensuring that policies and clinical practices facilitate abortion access for immigrants will serve to better support the reproductive health needs of all women.
\end{abstract}

Keywords: immigrants, abortion, characteristics

\section{Introduction}

A LTHOUGH IMMIGRANTS ACCOUNT for $17 \%$ of women of reproductive age in the United States and $23 \%$ of births, ${ }^{1}$ little is known about their use of abortion services. In the context of the U.S. health care system, immigrants are more likely to be uninsured, to receive culturally and linguistically inappropriate care, and to make fewer health care visits relative to the U.S.-born population. ${ }^{2-4}$

Immigration policies may contribute to these inequities. ${ }^{3}$ For example, immigrants are barred from using public insurance programs, such as Medicaid, based on their legal status or duration of residence in the United States. ${ }^{5}$ Stricter enforcement of federal immigration laws, coupled with increased state-level anti-immigrant legislation, has been shown to deter immigrants and their families from seeking needed health care for fear of discrimination or legal action. 6,7 Combined with mounting legal restrictions on abortion, ${ }^{8}$ the present political climate could widen disparities in reproductive health access and outcomes between immigrants and nonimmigrants.

Research on the reproductive health of immigrant women suggests that they are less likely than nonimmigrants to use sexual and reproductive health services such as contraceptive counseling, reproductive cancer and sexually transmitted infection screenings, and pre- and postnatal care. ${ }^{9-12}$ A recent study also found that undocumented women are less likely than other immigrant groups to obtain adequate levels of prenatal care. ${ }^{13}$ Indeed, immigrants in the United States are not a monolith and heterogeneity in immigration status, length of stay in the United States, country of origin, and

Guttmacher Institute, New York, New York.

(c) Sheila Desai et al. 2019; Published by Mary Ann Liebert, Inc. This Open Access article is distributed under the terms of the Creative Commons Attribution Noncommercial License (http://creativecommons.org/licenses/by-nc/4.0/) which permits any noncommercial use, distribution, and reproduction in any medium, provided the original author(s) and the source are cited. 
other dimensions of the immigration experience could constrain some groups' use of services more than others.

When reproductive health services are obtained, a higher proportion of immigrant than nonimmigrant women seek care from publicly funded clinics, which are also considered the usual source of medical care for almost three-quarters of foreignborn women. ${ }^{14}$ Immigrant women may face even greater difficulty than before to obtain routine reproductive health care, given recent policy efforts to curb Title $\mathrm{X}$ funding for comprehensive family planning services and restrict public funding to providers such as Planned Parenthood health centers. ${ }^{15}$

On the surface, it would seem that differences in reproductive health care use and access may not extend to abortion care insofar as immigrants obtain abortions at a rate comparable with nonimmigrants. ${ }^{16}$ Yet, despite similar use of abortion services, identifying differences between immigrants and nonimmigrants obtaining abortions is necessary to assess the reproductive health service and policy needs of immigrants in the United States. The majority of women obtaining abortions in the United States are in their 20s, unmarried, people of color, graduates of high school, and already parents. ${ }^{17,18}$ However, it is unknown whether immigrant women obtaining abortions have the same demographic profile. To that end, this study aims to describe the characteristics of immigrants obtaining abortions in the United States in 2008 and 2014 and compare these to nonimmigrants obtaining abortions during the same time period.

This article builds on prior studies of individuals obtaining abortions in the United States by focusing on a population that has not previously been examined in the published literature on abortion, addressing a critical gap in both immigrant and reproductive health research. Findings from this study may help inform health policies and clinical practices to better serve and support the reproductive health needs of immigrants. Furthermore, the continued rise in abortion restrictions, coupled with stricter immigration-related policies, could adversely impact immigrants' ability to obtain abortion services or make it more difficult for certain subgroups than others to do so. Findings from this study should provide important baseline data to identify future changes in the profile of immigrants obtaining abortions in the United States, which could also inform emergent policy issues affecting this population.

\section{Materials and Methods}

Data for this analysis came from the Guttmacher Institute's 2008 and 2014 Abortion Patient Survey (APS), a national sample of individuals obtaining abortions in the United States. Both rounds of data collection used a similar sampling design, questionnaire, and fieldwork protocol to that of previous APS surveys in 1987, 1994-1995, and 2000-2001. ${ }^{18-21}$ One notable exception was that the 2014 survey did not include individuals obtaining abortions in hospitals. As hospital abortions made up only $4 \%$ of total abortions in that year, excluding these facilities from the sampling frame was not expected to have a substantive impact. ${ }^{22}$ Participating facilities were randomly selected and recruited, and all women obtaining abortions at these facilities during a specified fielding period were asked to complete a four-page, paperand-pencil, self-administered questionnaire, available in English and Spanish. Respondents were provided with a sealable envelope in which to return the survey so that their responses would not be seen by staff. The 2008 APS had a $74 \%$ respondent response rate; the survey collected information from 9,493 respondents from 95 abortion care facilities across the United States. The 2014 APS collected information from 8,380 respondents from 87 nonhospital abortion care facilities for a $76 \%$ respondent response rate. Data from each survey round were weighted to create a nationally representative sample of abortion patients in 2008 and 2014. A detailed description of the data collection and weighting procedures can be found in previously published studies. ${ }^{17}$ The APS and data collection procedures were approved by the Guttmacher Institute's Institutional Review Board.

To robustly study the characteristics of immigrants obtaining abortions, we pooled the 2008 and 2014 APS data to increase the sample size of immigrants. The demographic profiles of all abortion patients in 2008 and 2014 have been previously compared and found to be similar. While a smaller proportion APS respondents in 2014 were adolescents and uninsured, and a larger proportion were poor, ${ }^{16,17}$ these changes were attributed to changes in the abortion patient population, not to differences in the survey design. We constructed new probability weights to appropriately account for the change in the number of abortions from $2008(N=1,212,350)$ to $2014(N=926,187)$ using two steps: (1) dividing the number

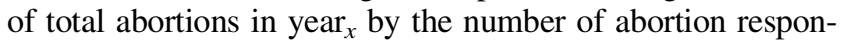
dents in the APS from year $x$ (where $x$ is either 2008 or 2014); and (2) multiplying this adjustment factor by the existing weights in each APS round. Although hospitals were not sampled in the 2014 APS, the hospital data from 2008 were retained in the pooled sample as $4.5 \%$ of immigrant respondents from that survey round obtained care at a hospital. The pooled sample included a total of 17,873 individuals who had obtained an abortion in 2008-2009 and 2013-2014.

Nativity status was constructed based on responses to the yes/no survey question: "Were you born in the United States?" Respondents who answered "yes" were categorized as U.S.born and those who answered "no" as immigrants. Some 426 respondents, $2 \%$ of the sample, did not answer this question, responses were imputed using the information from respondents with similar characteristics (see description of imputation strategy in the next paragraph). We conducted a sensitivity analysis that excluded cases with missing information on this variable, and the findings were unaltered (not shown). Immigrants comprised $16 \%(n=2,790)$ of the analytic sample, proportional to the share of immigrants in the U.S. population of women of reproductive age during both time periods. ${ }^{16,23}$ We examined key demographics, including age, race and ethnicity, health insurance status, relationship status, poverty level (measured relative to an annual income of $\sim \$ 24,000$ for a four-person household, as per the Health and Human Services poverty guidelines ${ }^{24}$ ), level of education (among women 20 years and older), residence in a Metropolitan Statistical Area (MSA), region of residence, survey language, and length of stay in the United States (for immigrants only).

We also assessed differences by nativity status in select situational variables such as gestation when the abortion was obtained (categorized as $\leq 12,13-15$, and $\geq 16$ weeks since the last menstrual period), prior births ( $0,1-2$, and $\geq 3$ births), prior abortions (yes or no), distance traveled to obtain services ( $<25,25-49,50-100$, and $>100$ miles), experience of intimate partner violence (yes or no), and exposure to disruptive life events experienced over the last year $(0,1, \geq 2$ 
events). Disruptive life events included exposure to any of eight events such as death of a friend, financial difficulties, and medical issues. We also examined if and how respondents had ever attempted to self-manage an abortion; although abortion is legal in the United States, some individuals still obtain, or attempt to obtain, abortions outside of formal clinic settings. ${ }^{25}$ In addition, immigrant women who previously resided in a country where abortion was so restricted as to be practically illegal may have had no option but to rely on self-managed abortion before emigrating.

Most variables had missing information for $\sim 1 \%-4 \%$ of cases. Three exceptions were distance traveled to obtain an abortion, family income, and length of stay in the United States, with missing values of $10 \%, 14 \%$, and $19 \%$, respectively. Missing values for all key demographic variables, including family income, were imputed using a "hot-deck" procedure. This strategy identifies variables most strongly associated with each item requiring imputation, and sorts the data file accordingly to replace the missing value with that from a similar, adjacent case. Analysis of variables that were not imputed-length of stay, distance traveled, exposure to intimate partner violence, and prior attempts of self-managed abortion-excluded individuals who did not answer the relevant question(s). We conducted a sensitivity analysis that excluded respondents who had imputed values on the variables of age, race and ethnicity, health insurance, union status, income/poverty, education, gestation, and prior births and abortions. Patterns between immigrants and nonimmigrants were virtually the same on all characteristics.

In this article, we compare the demographic and reproductive health profiles of immigrant and U.S.-born individuals receiving abortion services in the United States in 2008 and 2014, with a focus on describing the characteristics and circumstances of immigrants. We use chi-square to test for significant associations between respondent characteristics and nativity status. Differences were considered significant at a level of $p<0.05$. All analyses were conducted using Stata version 15.1 and weighted to account for individual-level nonresponse, variation from the original facility sampling plan, and the change in number of abortions between 2008 and 2014.

To assess if demographic differences by nativity status were proportional to differences in the underlying population of immigrant and nonimmigrant women in the United States, we conducted a sensitivity analysis comparing the percent distribution of these groups in the pooled APS sample to the percent distribution of these groups in the American Community Survey (ACS) across select demographic characteristics. Full methodological details for the ACS are available through the U.S. Census Bureau. ${ }^{26}$ We pooled the 2008 and 2014 1-year supplemental files of the ACS to estimate distributions of age group, race and ethnicity, poverty status, education level (among women 20 years and older), and region of residence. Comparisons were calculated as the proportion of immigrant abortion patients in a given subgroup (e.g., a particular age group) relative to the proportion of all reproductive-aged (15-44 years) immigrant women in the United States in that same subgroup. If the ratio from this comparison was the same as that for nonimmigrants, the difference in the distribution of this characteristic by nativity status was considered proportional to the difference observed between immigrants and nonimmigrants in the underlying population. Ratios that were not similar would suggest that the observed difference between immigrant and nonimmigrant abortion patients was specific to women seeking abortion.

\section{Results}

The majority of immigrants obtaining abortions were in their 20 s $(51 \%)$, had poverty-level $(<100 \%$ of the federal poverty level [FPL]) $(50 \%)$ or near poverty-level $(100 \%-$ $199 \%$ of the FPL) incomes (23\%), and had graduated from high school (78\%). Most commonly, immigrants in the sample were Hispanic (49\%) and one in five was Asian $(20 \%)$. They were about equally likely to live in the south $(33 \%)$ or west $(31 \%)$ of the country. Almost half $(45 \%)$ were uninsured and a similar proportion had been in the United States for less than 10 years (44\%); nearly one-quarter completed their survey in Spanish. This demographic profile was substantially different from that of U.S.-born individuals obtaining abortions (Table 1). While the majority of both groups were in their 20s, a larger proportion of immigrants were older; $40 \%$ were aged 30 and older compared with $23 \%$ of nonimmigrants. As noted, immigrant women were predominantly Asian and Hispanic, while the most common racial identities among nonimmigrants were non-Hispanic white (43\%) and non-Hispanic black (31\%). Furthermore, compared with immigrant women, a smaller share of nonimmigrants obtaining abortions lacked insurance coverage (32\%) and were not married (31\% vs. 12\%). Although the majority of both groups had attended some college or obtained a college degree, a larger proportion of immigrants (ages 20 and older) had not completed high school $(22 \%$ vs. $8 \%)$. A smaller proportion of immigrants $(7 \%)$ compared with nonimmigrants (17\%) lived in the Midwest region of the country. Each of these associations was significant at $p<0.001$.

With the exception of variations by race and ethnicity and poverty level, the demographic differences reflected those in the composition of the underlying population of immigrant and nonimmigrant women in the United States. For example, a higher proportion of immigrant abortion patients did not have a high school degree compared with nonimmigrants, and this educational difference was also seen among the larger population of U.S. women. Similar to the demographic profile of all individuals seeking abortion in the United States, ${ }^{17}$ a larger share of immigrants in our sample were younger and had poverty-level incomes compared with the population of immigrant women in the United States (Appendix Table A1).

Nearly all immigrants $(92 \%)$ in our sample had their abortion in the first trimester ( $\leq 12$ weeks) and $80 \%$ traveled under 25 miles for their procedure (Table 2). Over half (68\%) were already parents and $52 \%$ had not had a prior abortion. Less than $2 \%$ reported ever having attempted to self-manage an abortion. These patterns differed from nonimmigrants on most characteristics. A smaller proportion of immigrants compared with nonimmigrants had their abortions after 12 weeks ( $8 \%$ vs. $11 \%$ ) or traveled over 50 miles for the procedure (9\% vs. 16\%) (chisquare $p<0.001)$. Some $41 \%$ of nonimmigrants had not had a prior birth compared with $33 \%$ of immigrants (chi-square $p<0.001$ ); still, the majority of women in both groups were already parents. Although nearly one-third of each group reported exposure to one disruptive event in the last year, $25 \%$ of nonimmigrants reported exposure to two or more events compared with $15 \%$ of immigrants (chi-square $p<0.001$ ). Notably, there was no difference between the proportion of immigrant 
Table 1. Weighted Distribution of Immigrants and Nonimmigrants Obtaining Abortions in U.S. Facilities by Selected Demographic Characteristics, 2008-2014

\begin{tabular}{|c|c|c|c|c|c|}
\hline \multirow[b]{3}{*}{ Characteristic } & \multicolumn{5}{|c|}{ All abortion patients $(\mathrm{N}=17,873)$} \\
\hline & \multicolumn{2}{|c|}{ Immigrants $^{\mathrm{a}}(\mathrm{n}=2,790)$} & \multicolumn{2}{|c|}{ Nonimmigrants $^{\mathrm{a}}(\mathrm{n}=15,083)$} & \multirow[b]{2}{*}{$\mathrm{p}$} \\
\hline & $\mathrm{N}$ & $\%$ & $\mathrm{~N}$ & $\%$ & \\
\hline \multicolumn{6}{|l|}{ Age, years } \\
\hline$<18$ & 76 & 3 & 857 & 6 & $<0.001$ \\
\hline $18-19$ & 152 & 5 & 1,570 & 11 & \\
\hline $20-24$ & 692 & 24 & 5,406 & 35 & \\
\hline $25-29$ & 759 & 27 & 3,773 & 25 & \\
\hline $30-34$ & 554 & 20 & 2,001 & 13 & \\
\hline$\geq 35$ & 557 & 20 & 1,476 & 10 & \\
\hline \multicolumn{6}{|l|}{ Race/ethnicity } \\
\hline Hispanic & 1,361 & 49 & 2,928 & 20 & $<0.001$ \\
\hline Asian & 554 & 20 & 340 & 2 & \\
\hline Non-Hispanic black & 428 & 15 & 4,726 & 31 & \\
\hline Non-Hispanic white & 296 & 10 & 6,510 & 42 & \\
\hline Other $^{\mathrm{b}}$ & 151 & 6 & 579 & 4 & \\
\hline \multicolumn{6}{|l|}{ Health insurance } \\
\hline No coverage & 1,236 & 45 & 4,805 & 32 & $<0.001$ \\
\hline Medicaid & 756 & 27 & 5,067 & 34 & \\
\hline Private & 766 & 27 & 4,968 & 32 & \\
\hline HealthCare.gov/State exchange ${ }^{c}$ & 32 & 1 & 243 & 1 & \\
\hline \multicolumn{6}{|l|}{ Relationship status } \\
\hline Married & 845 & 30 & 1,739 & 12 & $<0.001$ \\
\hline Cohabiting, not married & 655 & 24 & 4,706 & 31 & \\
\hline Never-married, not cohabiting & 892 & 32 & 7,243 & 48 & \\
\hline Previously married, not cohabiting & 398 & 14 & 1,395 & 9 & \\
\hline \multicolumn{6}{|l|}{ Poverty status, $\%$} \\
\hline$<100$ & 1,402 & 50 & 6,769 & 45 & $<0.01$ \\
\hline 100-199 & 657 & 23 & 4,019 & 27 & \\
\hline$\geq 200$ & 731 & 27 & 4,295 & 29 & \\
\hline \multicolumn{6}{|l|}{ Highest level of education ${ }^{\mathrm{d}}$} \\
\hline Less than high school & 561 & 22 & 1,017 & 8 & $<0.001$ \\
\hline High school graduate/GED & 682 & 26 & 3,603 & 29 & \\
\hline Some college & 693 & 27 & 5,526 & 43 & \\
\hline College graduate & 626 & 25 & 2,510 & 20 & \\
\hline \multicolumn{6}{|l|}{ Resides in MSA } \\
\hline No & 163 & 6 & 1,720 & 12 & $<0.001$ \\
\hline Yes & 2,327 & 94 & 12,090 & 88 & \\
\hline \multicolumn{6}{|l|}{ Region of residence } \\
\hline Northeast & 698 & 27 & 3,325 & 23 & $<0.001$ \\
\hline Midwest & 266 & 9 & 2,534 & 17 & \\
\hline South & 903 & 33 & 5,469 & 36 & \\
\hline West & 917 & 31 & 3,755 & 24 & \\
\hline \multicolumn{6}{|l|}{ Survey language } \\
\hline English & 2,105 & 76 & 15,026 & 99.6 & $<0.001$ \\
\hline Spanish ${ }^{\mathrm{e}}$ & 685 & 24 & 57 & 0.4 & \\
\hline \multicolumn{6}{|l|}{ Length of stay in the United States ${ }^{f}$} \\
\hline$<5$ years & 490 & 22 & - & - & - \\
\hline $5-9$ years & 498 & 22 & - & - & \\
\hline $10+$ years & 1,283 & 56 & - & - & \\
\hline
\end{tabular}

${ }^{a}$ Counts may not sum to the total number of abortion patients due to missing data.

${ }^{\mathrm{b}}$ Includes respondents who identified as American Indian or Alaskan Native, Native Hawaiian or Pacific Islander, or other race.

${ }^{\mathrm{c}}$ These data were only collected in 2014 .

${ }^{\mathrm{d}}$ Among women ages 20 years or older.

' Includes seven respondents who completed the survey in Portuguese.

fOnly asked of foreign-born (i.e., immigrant) respondents.

MSA, metropolitan statistical area. 
Table 2. Weighted Distribution of Immigrants and Nonimmigrants Obtaining Abortions in U.S. Facilities by Select Reproductive Health and Situational Characteristics, 2008-2014

\begin{tabular}{|c|c|c|c|c|c|}
\hline & \multicolumn{5}{|c|}{ All abortion patients $(\mathrm{N}=17,873)$} \\
\hline & \multicolumn{2}{|c|}{ Immigrants $^{\mathrm{a}}(\mathrm{n}=2,790)$} & \multicolumn{2}{|c|}{ Nonimmigrants $^{\mathrm{a}}(\mathrm{n}=15,083)$} & \multirow[b]{2}{*}{$\mathrm{p}$} \\
\hline & $\mathrm{N}$ & $\%$ & $\mathrm{~N}$ & $\%$ & \\
\hline \multicolumn{6}{|l|}{ Gestation (weeks since LMP) } \\
\hline$\leq 12$ weeks & 2,568 & 92 & 13,510 & 89 & $<0.001$ \\
\hline $13-15$ weeks & 123 & 4 & 954 & 6 & \\
\hline$\geq 16$ weeks & 99 & 4 & 619 & 4 & \\
\hline \multicolumn{6}{|l|}{ Prior births } \\
\hline 0 & 930 & 33 & 6,241 & 41 & $<0.001$ \\
\hline $1-2$ & 1,597 & 58 & 7,920 & 53 & \\
\hline$\geq 3$ & 263 & 9 & 922 & 6 & \\
\hline \multicolumn{6}{|l|}{ Prior abortions } \\
\hline No & 1,369 & 52 & 7,715 & 53 & 0.827 \\
\hline Yes & 1,216 & 48 & 6,756 & 47 & \\
\hline \multicolumn{6}{|c|}{ Prior attempt to self-manage an abortion } \\
\hline Yes, using misoprostol & 29 & 1 & 142 & 1 & 0.733 \\
\hline Yes, using other substances & 21 & 1 & 98 & 1 & \\
\hline No attempt & 2,740 & 98 & 14,843 & 98 & \\
\hline \multicolumn{6}{|l|}{ Distance traveled to facility } \\
\hline$<25$ miles & 1,974 & 80 & 9,484 & 70 & $<0.001$ \\
\hline 25-49 miles & 268 & 11 & 1,931 & 14 & \\
\hline 50-100 miles & 120 & 5 & 1,316 & 9 & \\
\hline $100+$ miles & 110 & 4 & 945 & 7 & \\
\hline \multicolumn{6}{|c|}{ Experience of intimate partner violence ${ }^{\mathrm{b}}$} \\
\hline No & 2,496 & 95 & 13,722 & 94 & 0.181 \\
\hline Yes & 146 & 5 & 908 & 6 & \\
\hline \multicolumn{6}{|l|}{ Exposure to disruptive life events ${ }^{\mathrm{c}}$} \\
\hline 0 events & 1,462 & 53 & 6,450 & 43 & $<0.001$ \\
\hline 1 event & 904 & 32 & 4,816 & 32 & \\
\hline$\geq 2$ events & 424 & 15 & 3,817 & 25 & \\
\hline
\end{tabular}

${ }^{a}$ Counts may not sum to the total number of abortion patients due to missing data.

${ }^{\mathrm{b}}$ By the man with whom respondent became pregnant.

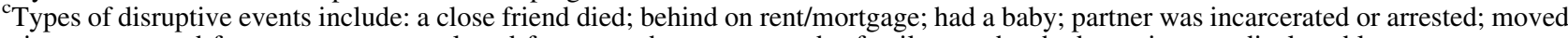
$2+$ times; separated from partner; unemployed for a month or more; and a family member had a serious medical problem.

LMP, last menstrual period.

and nonimmigrant women who reported a prior attempt to selfmanage their abortion or reported intimate partner violence.

\section{Discussion}

Individuals obtaining abortion in the United States have long been an economically and socially marginalized population. ${ }^{17,21,23}$ Combined data from the 2008 and 2014 national surveys of individuals obtaining abortions suggest that some of these vulnerabilities were even more pronounced for respondents born outside of the United States. In particular, a larger proportion of immigrants in the APS had not graduated from high school and did not have health insurance. The latter may be influenced by policies such as the 5-year ban on Medicaid that bars many immigrants from eligibility for public health insurance programs, as well as immigration enforcement that deters participation in these programs. ${ }^{27}$

The data also find that a higher proportion of immigrants obtaining abortions had family incomes below the FPL. Immigrant status can constrain options for employment or limit opportunities to low-wage jobs, which could impact family incomes. The overwhelming majority of immigrants in our sample were women of color; given the pervasive history of racism and xenophobia in the United States, these individuals may face discrimination and hostility based on their race, culture, and nativity, in general and within the medical system, that could impede their access to other reproductive health care. ${ }^{28-30}$ Similarly, that nearly one in five immigrants filled out the survey in Spanish could indicate that some have limited proficiency in English. Such language barriers could serve as an additional source of discrimination and also limit individuals' ability to find and obtain necessary care in communities and health systems where only English is used.

Immigrants obtaining abortions differed from their U.S.born counterparts in several other ways. That immigrants were older reflects the age distribution of the underlying population, and may indicate, for example, how some immigrants do not enter the United States until adulthood. Abortion patients born outside of the United States were more likely to live in a metropolitan area compared with U.S.-born individuals and, relatedly, they traveled shorter distances to obtain care. These patterns may reflect the concentration of immigrants in urban areas, which also have a higher density of abortion providers. ${ }^{31}$ This proximity to abortion services may help offset other 
potential barriers to care. Alternately, it is possible that immigrants were unable to find abortion providers located outside of their metropolitan area or, even if located, lacked the resources to travel for care. ${ }^{32}$ Indeed, previous research found that white, educated, and higher income women - groups that traditionally have access to resources and privilege-travel farther for abortion services than their counterparts. ${ }^{33,34}$

Our findings suggest that a smaller proportion of immigrants in the APS obtain abortions after the first trimester compared with those U.S.-born. Similar to the above, it is possible that the higher cost of second-trimester abortions, coupled with the lack of facilities that provide this care, requires individuals to travel farther for their abortion, potentially making these services less accessible to immigrant women. Alternately, as immigrant abortion patients were older and a higher proportion had had children, it is possible they were able to recognize their pregnancies earlier than nonimmigrants. Subsequent research should explore the factors that contribute to patterns in gestation among immigrants and nonimmigrants obtaining abortions.

There were several characteristics on which immigrant and U.S.-born respondents did not differ or differed in unexpected ways. Among both groups, similar proportions reported having a prior abortion and, despite prior evidence, ever attempting to self-manage an abortion. ${ }^{35}$ Given that some immigrants in our sample undoubtedly came from countries where abortion is highly restricted, we expected a lower proportion to have had a prior abortion but a higher proportion to report prior attempts to self-induce. The proportion of immigrant and U.S.-born abortion patients who reported experiencing intimate partner violence was comparable, and the proportion of immigrants who reported experiencing one or more disruptive events in the past year was lower than that for U.S.-born individuals. However, none of the experiences we asked about pertained directly to immigration-related stressors (e.g., had to produce proof of legal residency or family separation), and, in turn, we may have not captured the full range of disruptive events for this population. Alternately, since immigrants were older and a higher proportion was married compared with nonimmigrants, they may have had more stable lives and experienced fewer disruptive events.

This study has several limitations. Perhaps most importantly, it only contains data from individuals who were able to access clinical abortion services. Women who wanted an abortion but were unable to have one-whether due to lack of information, economic resources, or providers in their geographic area-were not captured in these data. Similarly we did not obtain information from individuals who were able to successfully self-manage their abortions outside of a clinical setting. Immigrants could be differentially excluded from this study if they are more likely than their counterparts to obtain abortions in nonclinical settings or face barriers that altogether prevent access to abortion. It is also possible that respondents born outside of the United States provided inaccurate information on their nativity status or were more likely than nonimmigrants to decline to fill out the survey. Similarly, the survey may have been too time-consuming or difficult to complete for individuals for whom English (or Spanish) was not their primary language. Such language barriers could differentially impact survey and study participation among immigrants compared with nonimmigrants. Furthermore, we were unable to examine specific immigrant groups in this study, despite the heterogeneity of the immigrant population. Because of substantial missing data on length of stay in the
United States; small cell sizes by their race and ethnicity; and no data on country of origin, or immigration status (our survey did not collect this information), we were unable to disaggregate our analyses by these factors, which have been documented to influence immigrants' health service use. ${ }^{9}$ Still, our study provides more information about immigrants obtaining abortions than was previously known. Finally, combining noncontinuous abortion data from 2008 and 2014 may have masked temporal changes in the population of individuals obtaining abortions; however, we derived and used pooled weights as one approach to account for such population shifts.

\section{Conclusions}

For the last decade, nearly one in five individuals obtaining abortions was an immigrant, and findings from this study suggest several clinical implications. Nearly one-quarter of immigrants filled out the survey in Spanish, which suggests the need for multilingual clinic resources (e.g., consent forms, follow-up instructions) and staff to facilitate accessible and comprehensive care for all people seeking abortion. Similarly, fewer years of education and lower levels of insurance among immigrants may impose additional challenges to navigating the health care system, including abortion care. This study also provides an important baseline for comparing subsequent studies of immigrants obtaining abortions. Increased immigration enforcement has already had a documented chilling effect on health care use and access among immigrants. ${ }^{27,36}$ Further study of immigrants' abortion access, particularly related to the influence of immigration policy on abortion care as well as the experiences of immigrants who are unable to access this care, will be critical. This information will help bring to bear if and how the changing policy environments impact immigrant women's abortion use, and ultimately, better serve and support the reproductive health needs of all women seeking abortion.

\section{Acknowledgments}

The authors thank Dr. Laura D. Lindberg, Kinsey Hasstedt, and Rebecca Wind for reviewing and commenting on earlier versions of this article. Support for this project was provided, in part, by the Guttmacher Center for Population Research Innovation and Dissemination (NIH grant 5 R24 HD074034).

\section{Author Disclosure Statement}

No competing financial interests exist.

\section{References}

1. Livingston G. Over the past 25 years, immigrant moms bolstered births in 48 states. Pew Res Cent 2017. Available at: www.pewresearch.org/fact-tank/2017/08/29/over-the-past25-years-immigrant-moms-bolstered-births-in-48-states Accessed March 2, 2019.

2. Dehlendorf C, Rodriguez MI, Levy K, Borrero S, Steinauer J. Disparities in family planning. Am J Obstet Gynecol 2010;202:214-220.

3. Hasstedt K. Toward equity and access: Removing legal barriers to health insurance coverage for immigrants. Guttmacher Policy Rev 2013;16. Available at: www.guttmacher .org/gpr/2013/03/toward-equity-and-access-removing-legalbarriers-health-insurance-coverage-immigrants Accessed January 15, 2019. 
4. Kavanaugh ML, Zolna MR, Burke KL. Use of health insurance among clients seeking contraceptive services at Title X-funded facilities in 2016. Perspect Sex Reprod Health 2018;50:101-109.

5. United States Centers for Medicare and Medicaid Services. Health coverage for lawfully present immigrants. HealthCare.gov. Available at: www.healthcare.gov/immigrants/ lawfully-present-immigrants Accessed September 12, 2018.

6. Vargas ED, Sanchez GR, Juárez M. Fear by association: Perceptions of anti-immigrant policy and health outcomes. J Health Polit Policy Law 2017;42:459-483.

7. Morse A, Pimienta M, Chanda I. Report on state immigration laws 2017. Washington, D.C.: National Conference of State Legislatures. Available at: www.ncsl.org/documents/ immig/2017_Immigration_Report\%20FINAL.pdf Accessed March 2, 2019.

8. Nash E, Gold RB, Mohammed L, Ansari-Thomas Z, Cappello O. Policy trends in the states, 2017. New York, NY: Guttmacher Institute, 2018. Available at: www.guttmacher .org/article/2018/01/policy-trends-states-2017 Accessed January 15, 2019.

9. Tapales A, Douglas-Hall A, Whitehead H. The sexual and reproductive health of foreign-born women in the United States. Contraception 2018;98:47-51.

10. Reyes AM, Miranda PY. Trends in cancer screening by citizenship and health insurance, 2000-2010. J Immigr Minor Health 2015;17:644-651.

11. Kentoffio K, Berkowitz SA, Atlas SJ, Oo SA, Percac-Lima S. Use of maternal health services: Comparing refugee, immigrant and US-born populations. Matern Child Health J 2016;20:2494-2501.

12. Hasstedt K, Desai S, Ansari-Thomas Z. Immigrant women's access to sexual and reproductive health coverage and care in the United States. New York, NY: The Commonwealth Fund, 2018.

13. Korinek K, Smith KR. Prenatal care among immigrant and racial-ethnic minority women in a new immigrant destination: Exploring the impact of immigrant legal status. Soc Sci Med 1982 2011;72:1695-1703.

14. Frost JJ. U.S. women's use of sexual and reproductive health services: Trends, sources of care and factors associated with use, 1995-2010. New York, NY: Guttmacher Institute, 2013:62. Available at: www.guttmacher.org/report/ us-womens-use-sexual-and-reproductive-health-servicestrends-sources-care-and-factors Accessed September 12, 2018.

15. Gold RB, Hasstedt K. Publicly funded family planning under unprecedented attack. Am J Public Health 2017;107: 1895-1897.

16. Jones RK, Jerman J. Population group abortion rates and lifetime incidence of abortion: United States, 2008-2014. Am J Public Health 2017;107:1904-1909.

17. Jerman J, Jones RK, Onda T. Characteristics of US abortion patients in 2014 and changes since 2008. New York: Guttmacher Institute, 2016.

18. Jones RK, Finer LB, Singth S. Characteristics of U.S. abortion patients, 2008. New York, NY: Guttmacher Institute, 2010:28. Available at: www.guttmacher.org/report/characteristics-usabortion-patients-2008 Accessed November 17, 2018.

19. Henshaw SK, Silverman J. The characteristics and prior contraceptive use of U.S. abortion patients. Fam Plann Perspect 1988;20:158-168.

20. Henshaw SK, Kost K. Abortion patients in 1994-1995: Characteristics and contraceptive use. Fam Plann Perspect 1996;28:140-158.
21. Jones RK, Darroch JE, Henshaw SK. Patterns in the socioeconomic characteristics of women obtaining abortions in 2000-2001. Perspect Sex Reprod Health 2002;34:226-235.

22. Jones RK, Jerman J. Abortion incidence and service availability in the United States, 2014. Perspect Sex Reprod Health 2017;49:17-27.

23. Jones RK, Kavanaugh ML. Changes in abortion rates between 2000 and 2008 and lifetime incidence of abortion. Obstet Gynecol 2011;117:1358-1366.

24. United States Department of Health and Human Services. Prior HHS Poverty Guidelines and Federal Register References. 2015. ASPE. Available at: https://aspe.hhs.gov/ prior-hhs-poverty-guidelines-and-federal-register-references Accessed September 12, 2018.

25. Grossman D, Hendrick E, Fuentes L, et al. Knowledge, opinion and experience related to abortion self-induction in Texas. Contraception 2015;92:360-361.

26. United States Census Bureau. American Community Survey Design and Methodology. Washington, DC: United States Census Bureau, 2014. Available at: www2.census.gov/ programs-surveys/acs/methodology/design_and_methodology/ acs_design_methodology_report_2014.pdf Accessed January 15, 2019.

27. Watson T. Inside the refrigerator: Immigration enforcement and chilling effects in Medicaid participation. Am Econ J Econ Policy 2014;6:313-338.

28. Hall WJ, Chapman MV, Lee KM, et al. Implicit racial/ethnic bias among health care professionals and its influence on health care outcomes: A systematic review. Am J Public Health 2015;105:e60-e76.

29. Samari G, Alcalá HE, Sharif MZ. Islamophobia, health, and public health: A systematic literature review. Am J Public Health 2018;108:e1-e9.

30. Viruell-Fuentes EA, Miranda PY, Abdulrahim S. More than culture: Structural racism, intersectionality theory, and immigrant health. Soc Sci Med 1982 2012;75:2099-2106.

31. Pew Research Center. Modern immigration wave brings 59 million to U.S. Washington, D.C.: Pew Research Center, 2015. Available at: www.pewhispanic.org/2015/09/28/ modern-immigration-wave-brings-59-million-to-u-s-drivingpopulation-growth-and-change-through-2065 Accessed November 17, 2018.

32. Syed ST, Gerber BS, Sharp LK. Traveling towards disease: Transportation barriers to health care access. J Community Health 2013;38:976-993.

33. Jones RK, Jerman J. How far did US women travel for abortion services in 2008? J Womens Health (Larchmt) 2013;22:706-713.

34. Dehlendorf C, Harris LH, Weitz TA. Disparities in abortion rates: A public health approach. Am J Public Health 2013; 103:1772-1779.

35. Jones RK. How commonly do US abortion patients report attempts to self-induce? Am J Obstet Gynecol 2011;204: 23.e1-e23.e4.

36. Page KR, Polk S. Chilling effect? Post-election health care use by undocumented and mixed-status families. N Engl J Med 2017;376:e20.

Address correspondence to: Sheila Desai, DrPH Guttmacher Institute 125 Maiden Lane, 7th Floor New York, NY 10038

E-mail: sdesai@guttmacher.org (Appendix follows $\rightarrow$ ) 


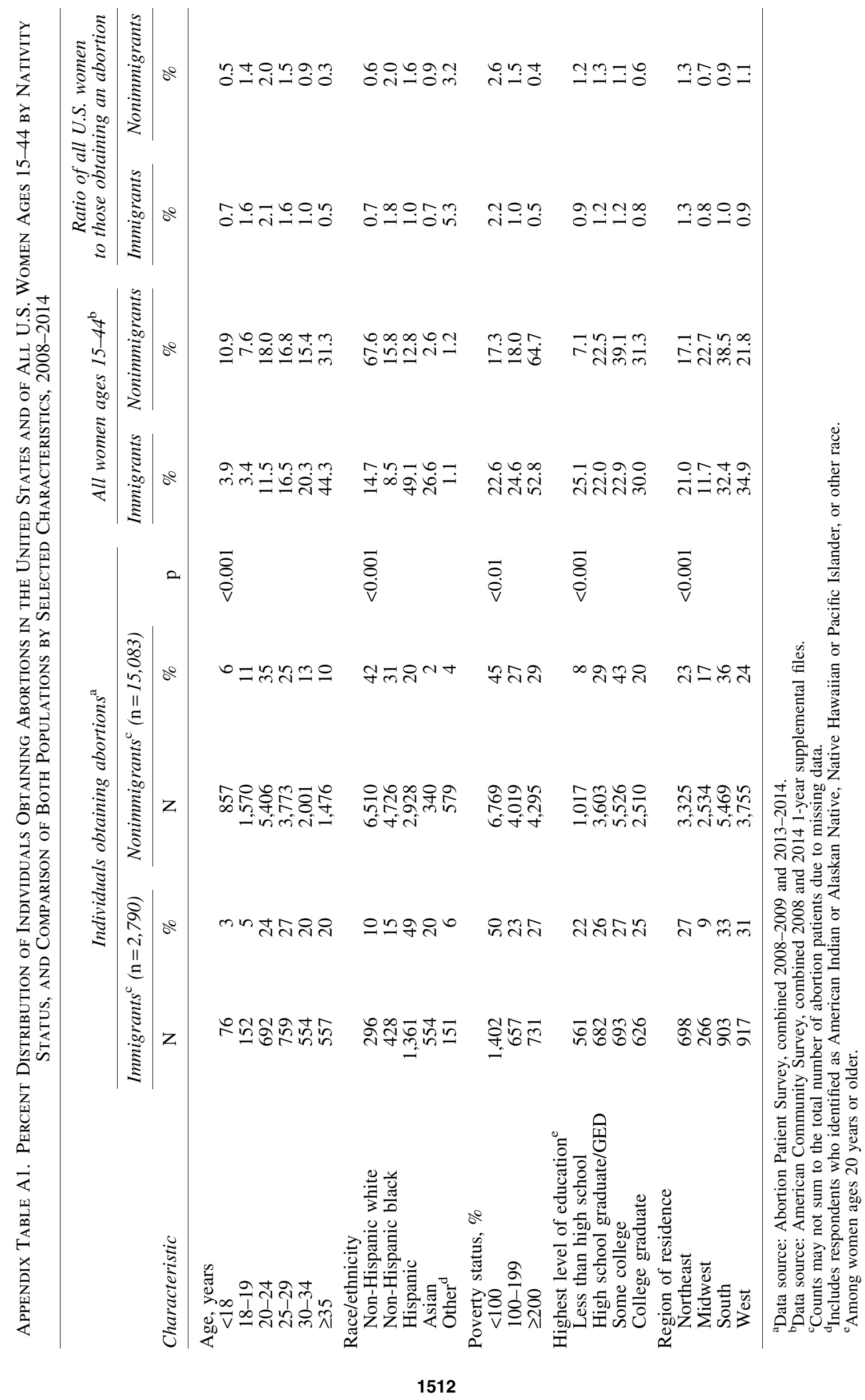

